\title{
A DESCRIPTION OF INTERPERSONAL VIOLENCE-RELATED HOSPITALISATIONS IN NEW SOUTH WALES
}

\author{
Andrew Hayen and Rebecca Mitchell \\ NSW Injury Risk Management Research Centre \\ University of New South Wales
}

Interpersonal violence (IPV) includes a range of acts and behaviours, including physical violence, and is the term used to describe the intentional use of force or power by one individual or a group of individuals on another person. ${ }^{1,2}$ Interpersonal violence has many contributing factors, often interrelated, which can include social, economic, political, cultural, and biological factors. ${ }^{2}$

Interpersonal violence and its effects on health are a growing concern to the public health sector. ${ }^{3}$ Worldwide, there are around 520,000 IPV-related deaths (homicides) each year (8.8 per 100,000 population) and many more individuals are hospitalised as a result of IPV. ${ }^{2}$

In NSW, the lifetime cost of fatal and non-fatal physical injuries due to IPV has been estimated at \$133.9 million$\$ 21.9$ million in direct costs and \$112 million in mortality and morbidity costs. ${ }^{4}$ Economic analyses of IPV-related prevention strategies have demonstrated that many IPVrelated interventions are cost-effective. ${ }^{5}$

This article provides a description of IPV-related hospitalisations in NSW that resulted from a physical injury and includes information on where the incident took place and the relationship of the assailant to the injured person.

\section{METHOD}

Hospitalisation data were obtained from the NSW Inpatient Statistics Collection (ISC) for the financial years 1989-90 to 2003-04. The ISC is a census (since July 1, 1993) of patients admitted to public and private hospitals, private day procedures, and public psychiatric hospitals in NSW. ${ }^{6}$

Hospitalisation data include information on episodes of care in hospital which end with the discharge, transfer, or death of the patient, or where the service category for the admitted patient changes. The ISC also includes hospitalisations of NSW residents that occurred in another state or territory. While these data were not available for 2003-04, the number of interstate hospitalisations for this year was imputed based on hospitalisations from the previous three years. A detailed description of the method of imputation used is available elsewhere. ${ }^{6}$

Interpersonal violence-related hospitalisations for NSW residents were identified using the following criteria, all of which had to be met:

- The hospitalisation was for a patient who was a resident of NSW.

- There was a principal diagnosis in the ICD-10-AM range S00-T98 (1998-99 to 2003-04) or in the ICD-9CM range 800-999 (for 1989-90 to 1997-98).
- There was an external cause code in the ICD-10-AM range X85-Y09 or Y87.1 (1998-99 to 2003-04) or in the ICD-9-CM range E960-E969 (for 1989-90 to 1997-98).

Hospitalisations relating to transfers or statistical discharges were excluded to eliminate 'multiple counts', which occur when an individual has more than one episode of care for a given injury. These exclusions refer to transfers between hospitals or changes in the service category for a patient during the one episode of accommodation in a single facility, respectively. ${ }^{6}$ For the years $1999-2000$ to 2003-04, the cause of IPV-related hospitalisations were categorised according to the method used to inflict injury (Table 1). Hospitalisations for IPV that ended in death were included in this analysis. Age- and sex-specific population estimates as at 31 December of each of the years under study were obtained from the NSW Department of Health and the Australian Bureau of Statistics. The place of occurrence of the incident for the years 2000-01 to 2003-04 and the relationship between the perpetrator and the victim of the violence for the years 2002-03 to 2003-04 were extracted. These were the years for which this information was available in the ISC.

Analyses were performed using SAS software. ${ }^{7}$ Directly age-standardised rates were calculated using the estimated Australian residential population as at 30 June 2001 as the standard population. Ninety-five per cent confidence intervals were calculated assuming a Poisson distribution. ${ }^{8}$ A negative-binomial regression analysis ${ }^{9}$ was performed to examine the statistical significance of changes in the trend over the time period 1989-90 to 2003-04, and to calculate the annual percentage change in the rate of hospitalisations.

\section{RESULTS}

During the period 1999-2000 to 2003-04, there were 29,701 hospitalisations due to IPV, at a rate of 90.8 per 100,000 population (Table 1 ). There were approximately 5,940 hospitalisations per year during 1999-2000 to 2003-04 due to IPV.

Rates of hospitalisation for IPV were almost three times higher in males than females for the period 1989-90 to 2003-04 (Figure 1). The hospitalisation rate was estimated to have increased significantly by 0.9 per cent each year for males (95 per cent CI for the annual increase: 0.3 per cent to 1.5 per cent), and increased significantly by 2.7 per cent each year for females ( 95 per cent CI for the annual increase: 1.9 per cent to 3.5 per cent).

Rates of hospitalisation for IPV were higher in males than females for all age groups during 1999-00 to 2003-04 
(Figure 2). Males aged 20-24 years had the highest hospitalisation rates for injuries due to IPV.

For the period 1999-2000 to 2003-04, IPV using bodily force accounted for just over half (58.0 per cent) of the hospitalisations due to IPV (Table 1). For males, bodily force represented over three-quarters of the hospitalisations for IPV. The overall hospitalisation rate for males was about 266 per cent higher than for females.

For females, the most common relationship between the perpetrator and the victim was spouse or domestic partner

\section{TABLE 1}

NUMBER AND RATE OF HOSPITALISATIONS FOR INJURY FOR MALES AND FEMALES IN NEW SOUTH WALES CAUSED BY DIFFERENT TYPES OF INTERPERSONAL VIOLENCE 1999-2000 TO 2003-04

\begin{tabular}{|c|c|c|c|c|c|c|c|c|c|}
\hline \multirow[b]{2}{*}{ Interpersonal violence method } & \multicolumn{3}{|c|}{ All persons } & \multicolumn{3}{|c|}{ Male } & \multicolumn{3}{|c|}{ Female } \\
\hline & $\mathbf{n}$ & Rate $^{*}$ & $95 \% \mathrm{Cl}$ & $\mathbf{n}$ & Rate* & $95 \% \mathrm{Cl}$ & $\mathbf{n}$ & Rate $^{*}$ & $95 \% \mathrm{Cl}$ \\
\hline $\begin{array}{l}\text { Bodily force } \\
\text { (Y04-Y05, Y07) }\end{array}$ & 17,238 & 52.7 & $51.9-53.5$ & 13,000 & 79.1 & 77.7-80.4 & 4,239 & 26.0 & $25.2-26.8$ \\
\hline $\begin{array}{l}\text { Sharp or blunt object } \\
(\mathrm{X} 99, \mathrm{Y} 00)\end{array}$ & 6,830 & 20.9 & $20.4-21.4$ & 5,870 & 35.7 & $34.8-36.7$ & 960 & 5.9 & $5.5-6.3$ \\
\hline \multicolumn{10}{|l|}{ Firearm } \\
\hline \multicolumn{5}{|l|}{ Poisoning } & 25.1 & $24.4-25.9$ & 1,039 & 6.3 & $5.9-6.7$ \\
\hline $\begin{array}{l}\text { Suffocation } \\
\text { (X91) }\end{array}$ & \multicolumn{5}{|c|}{ Suffocation } & $0.1-0.1$ & 24 & 0.1 & $0.1-0.2$ \\
\hline $\begin{array}{l}\text { Other } \\
\text { (All remaining IPV codes) }\end{array}$ & \multicolumn{3}{|c|}{ Other } & 4,132 & 25.1 & $24.4-25.9$ & 1,039 & 6.3 & $5.9-6.7$ \\
\hline All ${ }^{\ddagger}$ & 29,701 & 90.8 & $89.8-91.8$ & 23,356 & 142.1 & $140.3-143.9$ & 6,343 & 38.8 & $37.8-39.8$ \\
\hline \multicolumn{10}{|l|}{ * Rate per 100,000 population. } \\
\hline \multicolumn{10}{|c|}{$\begin{array}{l}\text { ₹ The number of NSW residents hospitalised interstate during 2003-04 was imputed and as a result the sum of sub mechanisms may not } \\
\text { equal the total. }\end{array}$} \\
\hline
\end{tabular}

\section{FIGURE 1}

HOSPITALISATION RATE* FOR INJURY DUE TO INTERPERSONAL VIOLENCE FOR MALES AND FEMALES, NEW SOUTH WALES 1989-90 TO 2003-04

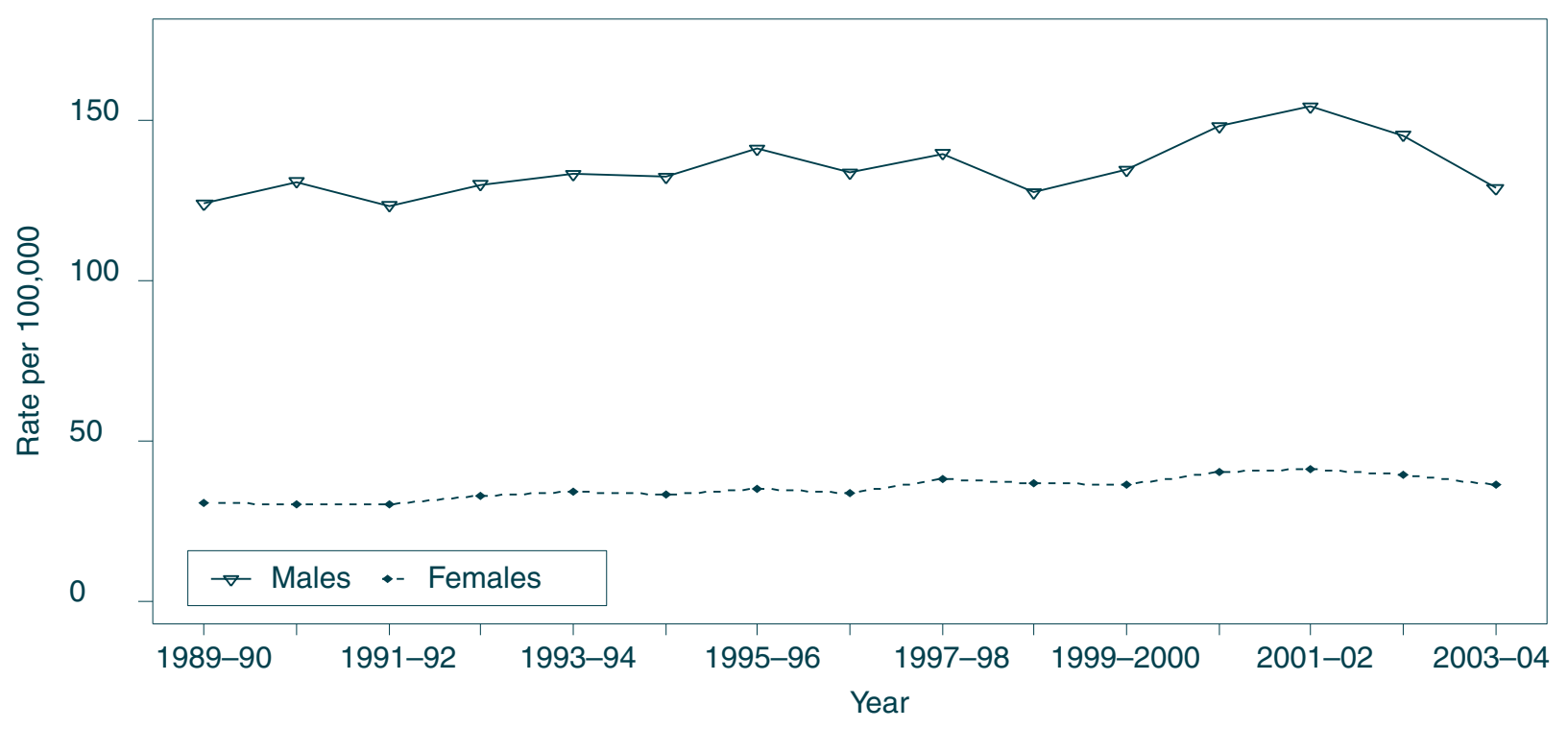

${ }^{*}$ Age-standardised rate per 100,000 population. 
FIGURE 2

AGE-SPECIFIC HOSPITALISATION RATE FOR INTERPERSONAL VIOLENCE FOR MALES AND FEMALES, NEW SOUTH WALES: 1999-00 TO 2003-04

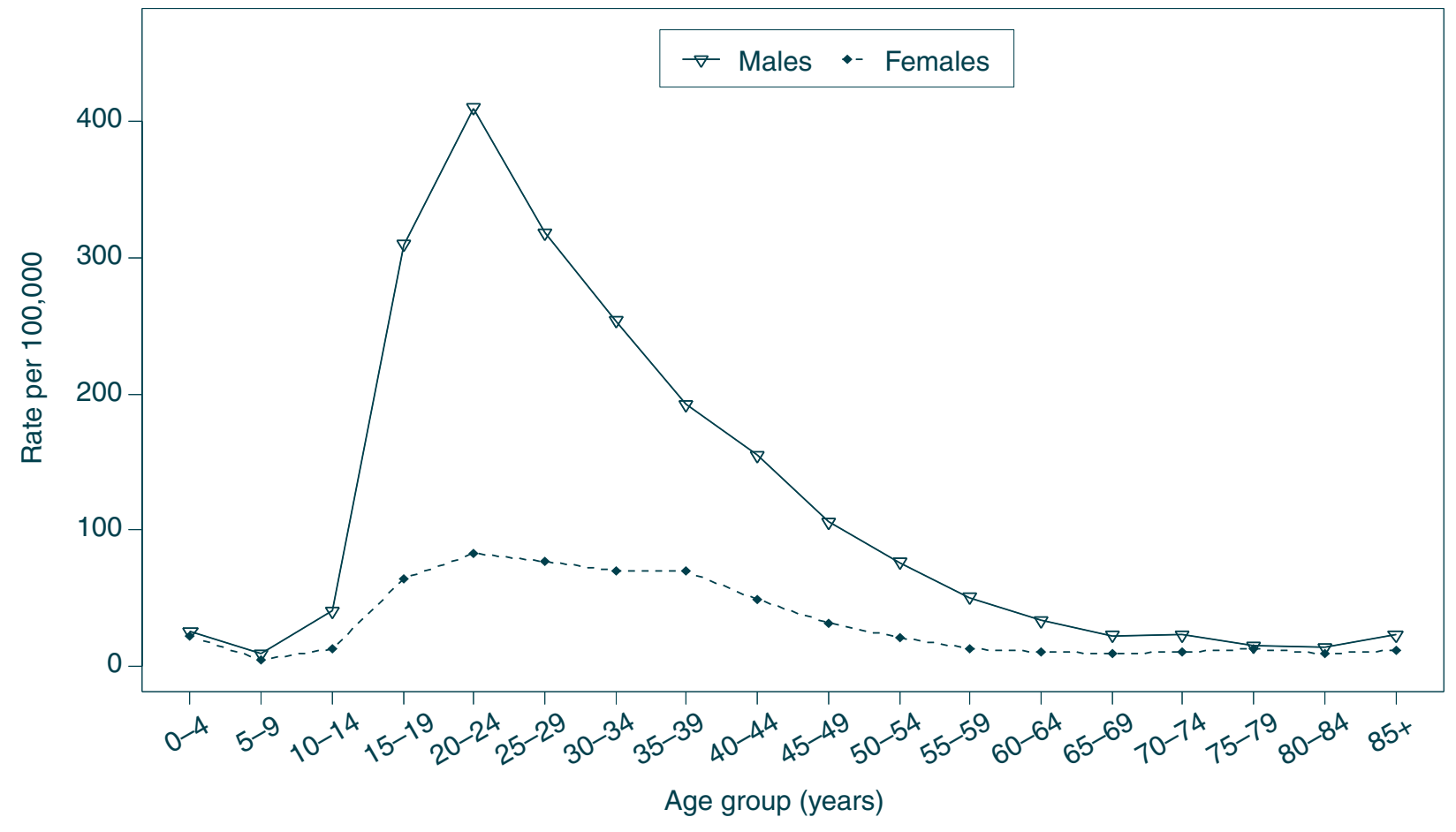

(39.2 per cent). For males, the relationship with the perpetrator was coded as 'unspecified person' for nearly two-thirds (65.1 per cent) of hospitalisations (Table 2).

Place of occurrence was recorded as unspecified for about half (49.2 per cent) of IPV-related hospitalisations in NSW from 2000-01 to 2003-04 (Table 3). For females, the most commonly recorded location was the home (42.2 per cent), while for males it was a trade or service area (13.5 per cent).

\section{DISCUSSION}

Interpersonal violence was the sixth leading cause of injury-related hospitalisation for the period 1999-00 to 2003-04, and accounted for 4.9 per cent of all injuryrelated hospitalisations. ${ }^{10}$ This analysis shows that IPV is one of the leading causes of injury-related hospitalisation in NSW. In the period 1989-90 to 2003-04, rates of IPVrelated hospitalisations increased significantly in NSW for both males and females. However, because of changes in coding and possible changes in hospital admission practices over time, caution should be exercised when interpreting these trends.

Bodily force was the most common method of IPV that caused hospitalisation for all age groups. The results suggest that males aged 15-44 years are a population at particular risk, as they had very high rates of hospitalisation compared to all other age groups. The very high rate of
IPV-related hospitalisation among males aged 20-24 years has been noted elsewhere and may be due to a number of factors including substance use, family-related factors, peer influence, and situational and exposure-related factors. ${ }^{11}$

Hospitalisations as a result of IPV only represent a proportion of the burden from this mode of injury. Interpersonal violence-related deaths accounted for 4 per cent of all injury-related deaths during 1999 to 2003 in $\mathrm{NSW}^{12}$, and the number of injuries as a result of IPV that do not require hospitalisation or where medical treatment was not sought (or available) has not been quantified in NSW. There is the potential in NSW to develop mechanisms that would assist in the estimation of the often less serious injuries that do not require hospitalisation. However, currently the number and rate of emergency department presentations and general practice visits in NSW caused by IPV are not easily obtainable across the state.

A better understanding of IPV-injuries that resulted in hospitalisation would also require information about the relationship between the perpetrator and the victim of the violence. Although this information became available in ISC data in 2002-03 with the introduction of ICD-10-AM $3^{\text {rd }}$ edition, the perpetrator of the violence was coded as an unspecified person for nearly two-thirds ( 65.1 per cent) of hospitalisations of males in 2002-03 and 2003-04. However, for females who were hospitalised the perpetrator of the violence was coded as an unspecified person in less 
TABLE 2

RELATIONSHIP OF THE ASSAILANT TO THE INJURED PERSON FOR INJURY HOSPITALISATIONS DUE TO INTERPERSONAL VIOLENCE IN NEW SOUTH WALES, 2002-03 TO 2003-04*

\begin{tabular}{|c|c|c|c|c|c|c|}
\hline & \multicolumn{2}{|c|}{ All persons } & \multicolumn{2}{|c|}{ Male } & \multicolumn{2}{|c|}{ Female } \\
\hline & $\mathbf{n}$ & $\%$ & $\mathbf{n}$ & $\%$ & $\mathbf{n}$ & $\%$ \\
\hline \multicolumn{7}{|c|}{ Relationship of the assailant to the injured person } \\
\hline Spouse or domestic partner & 1,150 & 10.1 & 185 & 2.1 & 965 & 39.2 \\
\hline Parent & 256 & 2.2 & 142 & 1.6 & 114 & 4.6 \\
\hline Other family member & 437 & 3.8 & 275 & 3.1 & 162 & 6.6 \\
\hline Carer & 20 & 0.2 & 5 & 0.1 & 15 & 0.6 \\
\hline Acquaintance or friend & 671 & 5.9 & 490 & 5.5 & 181 & 7.3 \\
\hline Official authorities & 66 & 0.6 & 61 & 0.7 & 5 & 0.2 \\
\hline Person unknown to the victim & 1,267 & 11.1 & 1,118 & 12.5 & 149 & 6.0 \\
\hline Multiple persons known to the victim & 500 & 4.4 & 465 & 5.2 & 35 & 1.4 \\
\hline Other specified person & 504 & 4.4 & 388 & 4.3 & 116 & 4.7 \\
\hline Unspecified person & 6,551 & 57.4 & 5,830 & 65.1 & 721 & 29.3 \\
\hline Total & 11,422 & 100.0 & 8,959 & 100.0 & 2,463 & 100.0 \\
\hline
\end{tabular}

\section{TABLE 3}

LOCATION OF THE INJURY INCIDENT FOR HOSPITALISATIONS DUE TO INTERPERSONAL VIOLENCE IN NEW SOUTH WALES, 2000-01 TO 2003-04*

\begin{tabular}{|c|c|c|c|c|c|c|}
\hline & \multicolumn{2}{|c|}{ All persons } & \multicolumn{2}{|c|}{ Male } & \multicolumn{2}{|c|}{ Female } \\
\hline & $\mathbf{n}$ & $\%$ & $\mathbf{n}$ & $\%$ & $\mathbf{n}$ & $\%$ \\
\hline \multicolumn{7}{|l|}{ Location of incident } \\
\hline Home & 4,724 & 18.0 & 2,387 & 11.5 & 2,337 & 42.2 \\
\hline Residential institution & 530 & 2.0 & 476 & 2.3 & 54 & 1.0 \\
\hline School, other institution and public administrative area & 558 & 2.1 & 464 & 2.2 & 94 & 1.7 \\
\hline Sports and athletics area & 225 & 0.9 & 206 & 1.0 & 19 & 0.3 \\
\hline Street and highway & 2,763 & 10.5 & 2,396 & 11.6 & 367 & 6.6 \\
\hline Trade and service area & 3,092 & 11.8 & 2,802 & 13.5 & 290 & 5.2 \\
\hline Industrial and construction area & 137 & 0.5 & 126 & 0.6 & 11 & 0.2 \\
\hline Other specified place of occurrence (including farm) & 1,171 & 4.5 & 1,000 & 4.8 & 171 & 3.1 \\
\hline Unspecified place of occurrence & 12,900 & 49.2 & 10,735 & 51.9 & 2,164 & 39.1 \\
\hline Missing & 137 & 0.5 & 104 & 0.5 & 33 & 0.6 \\
\hline Total & 26,237 & 100.0 & 20,696 & 100.0 & 5,540 & 100.0 \\
\hline
\end{tabular}

than one third of records (29.3 per cent). Because of this lack of detail, it is difficult to obtain accurate estimates of the rates of IPV according to the type of relationship between perpetrator and victim, such as 'intimate partner (domestic)' violence, 'family' violence, or 'community' violence, particularly for males.

The place of occurrence for an IPV-related hospitalisation is also recorded in hospitalisation data. Disappointingly, this variable was coded as 'unspecified' for around half (50.8 per cent) of IPV-related hospitalisations in NSW from 2000-01 to 2003-04. In addition, the level of specificity of coding does not allow detection of IPV-incidents at licensed premises, except through the multiple location code of 'trade and service area, cafe, hotel and restaurant'.

The design of relevant intervention strategies that are likely to be effective in preventing IPV relies on the ability to access detailed information regarding the IPV incident and its circumstances. Improved recording of the relationship between the victim and perpetrator of IPV-related injuries and the place of occurrence of an IPV incident in hospitalisation data would assist in the monitoring and subsequent prevention of IPV injuries in NSW. 


\section{ACKNOWLEDGEMENTS}

The authors were supported by the NSW Injury Risk Management Research Centre, with core funding provided by the NSW Department of Health, the NSW Roads and Traffic Authority and the Motor Accidents Authority.

The authors wish to thank the Centre for Epidemiology and Research at the NSW Department of Health for providing the data from the Health Outcomes and Information Statistical Toolkit (HOIST) analysed in this study.

\section{REFERENCES}

1. World Health Organization. International classification of diseases (ICD-10), 10th revision. Geneva: WHO, 1992.

2. World Health Organization. World report on violence and health. Geneva: WHO, 2002.

3. World Health Assembly. Prevention of violence: public health priority. (Resolution no. WHA 49.25). Geneva: WHO, 1996.

4. Potter-Forbes M, Aisbett C. Injury costs! A validation of the burden of injury in NSW, 1998-99. Sydney: NSW Injury Risk Management Research Centre, 2003.
5. World Health Organization. The economic dimensions of interpersonal violence. Geneva: WHO, 2004.

6. Population Health Division, NSW Department of Health. The health of the people of NSW. Report of the Chief Health Officer 2004. Sydney: NSW Department of Health, 2004.

7. SAS Institute. SAS: statistical software, version 8.02. Cary, North Carolina: SAS Institute, 2000.

8. Dobson A, Kuulasmaa K, Eberle E, Schere J. Confidence intervals for weighted sums of Poisson parameters. Stat Med 1991;10: 457-762.

9. Armitage P, Berry G, Matthews J. Statistical methods in medical research. Fourth Edition. Cornwell: Blackwell Science, 2002.

10. Hayen A, Mitchell R. NSW injury profile: A review of injury hospitalisations during 1989-90 to 2003-04. Sydney: NSW Injury Risk Management Research Centre; 2006.

11. Hawkins J, Herrenkohl T, Farrington D, Brewer D, Catalano $\mathrm{R}$, Harachi T, et al. Predictors of youth violence. Juvenile Justice Bulletin April 2000:1-12.

12. Schmertmann M, Finch C. A demographic profile of deaths due to interpersonal violence in New South Wales. $N S W$ Public Health Bull 2006; 17(1-2):4-7 娚

\section{DRUG-RELATED AGGRESSION AMONG INJECTING DRUG USERS}

\author{
Emma Black and Louisa Degenhardt \\ National Drug and Alcohol Research Centre \\ University of New South Wales
}

Recent years have seen the diversification of the methamphetamine markets in Australia, with increased availability and the use of more potent forms of methamphetamine such as ice/crystal and base methamphetamine. ${ }^{1}$ Intoxication due to the use of stimulants such as methamphetamine has been associated with aggressive and violent behaviour. The connection is not a direct causal relationship, but is thought to be influenced by a number of other factors such as individual, situational and cultural factors. ${ }^{2,3,4,5}$

As a consequence of these changes to the methamphetamine market, there has been understandable concern that there could also be a concomitant increase in aggressive behaviour among those using the drug.

An association between alcohol and aggression is established ${ }^{2,3}$, although a range of other factors, such as context, pharmacology and individual differences, also play a role. ${ }^{3,6,7}$ Evidence supporting a link between benzodiazepines and aggression is less conclusive. However, as with alcohol, a wide range of variables including age, genetics, mood, environment and personality characteristics, such as poor impulse control, have been implicated in modifying individual responses. ${ }^{8,3}$

This article examines associations between self-reported aggressive behaviour and substance use among an Australia-wide sample of injecting drug users (IDU), where substance-related aggression was defined as aggression while being either under the influence of a drug or during withdrawal.

\section{METHODS}

The study utilised the cross sectional survey component of the Illicit Drug Reporting System (IDRS), an annual survey of IDU in metropolitan Australia.

Participants were injecting drug users $(n=948)$ recruited in key drug market areas in capital cities in all Australian jurisdictions. To be eligible, participants had to have been injecting at least monthly during the six months preceding the interview and have lived for at least 12 months in the capital city in which they were interviewed. Data are presented here from 2004. The number of participants from each state or territory were: NSW 157, Victoria 150, Northern Territory 111, Queensland 129, Australian Capital Territory 100, South Australia 101, Tasmania 100, and 